\title{
Factors associated with disease evolution in Greek patients with inflammatory bowel disease
}

\author{
Constantinos Chatzicostas ${ }^{1}$, Maria Roussomoustakaki*2, \\ Spiros Potamianos ${ }^{2}$, Gregorios Paspatis ${ }^{3}$, Ioannis Mouzas ${ }^{2}$, John Romanos ${ }^{4}$, \\ Helen Mavrogeni ${ }^{5}$ and Elias Kouroumalis ${ }^{2}$
}

\begin{abstract}
Address: ${ }^{1}$ Department of Gastroenterology, General Hospital of Rethymnon, Rethymnon, Crete, Greece, ${ }^{2}$ Department of Gastroenterology, University Hospital of Heraklion, Heraklion, Crete, Greece, ${ }^{3}$ Department of Gastroenterology, Venizelion General Hospital, Heraklion, Crete, Greece, ${ }^{4}$ Department of Surgical Oncology, University Hospital of Heraklion, Heraklion, Crete, Greece and ${ }^{5}$ Department of Internal Medicine, General Hospital of Rethymnon, Crete, Greece

Email: Constantinos Chatzicostas - matrix01gr@yahoo.gr; Maria Roussomoustakaki* - mrousso1@ @hotmail.com; Spiros Potamianos - spot@lar.forthnet.gr; Gregorios Paspatis - paspatis@lyttos.admin.teiher.gr; Ioannis Mouzas - mouzas@med.uoc.gr; John Romanos - romanos@med.uoc.gr; Helen Mavrogeni - photeini@in.gr; Elias Kouroumalis - kouroum@med.uoc.gr

* Corresponding author
\end{abstract}

Published: 25 July 2006

BMC Gastroenterology 2006, 6:21 doi:| 0.1 |86/|47|-230X-6-2 I
Received: 04 April 2006

Accepted: 25 July 2006

This article is available from: http://www.biomedcentral.com/I47I-230X/6/2 I

(C) 2006 Chatzicostas et al; licensee BioMed Central Ltd.

This is an Open Access article distributed under the terms of the Creative Commons Attribution License (http://creativecommons.org/licenses/by/2.0), which permits unrestricted use, distribution, and reproduction in any medium, provided the original work is properly cited.

\begin{abstract}
Background: The majority of Crohn's disease patients with BI phenotype at diagnosis (i.e. nonstricturing non-penetrating disease) will develop over time a stricturing or a penetrating pattern. Conflicting data exist on the rate of proximal disease extension in ulcerative colitis patients with proctitis or left-sided colitis at diagnosis. We aimed to study disease evolution in Crohn's disease $\mathrm{BI}$ patients and ulcerative colitis patients with proctitis and left-sided colitis at diagnosis.
\end{abstract}

Methods: I 16 Crohn's disease and 256 ulcerative colitis patients were followed-up for at least 5 years after diagnosis. Crohn's disease patients were classified according to the Vienna criteria. Data were analysed actuarially.

Results: $\mathrm{BI}$ phenotype accounted for $68.9 \%$ of Crohn's disease patients at diagnosis. The cumulative probability of change in disease behaviour in $\mathrm{BI}$ patients was $43.6 \%$ at 10 years after diagnosis. Active smoking (Hazard Ratio: 3.0I) and non-colonic disease (non-L2) (Hazard Ratio: 3.0I) were associated with behavioural change in $\mathrm{BI}$ patients. Proctitis and left-sided colitis accounted for $24.2 \%$, and $48.4 \%$ of ulcerative colitis patients at diagnosis. The 10 year cumulative probability of proximal disease extension in patients with proctitis and left-sided colitis was $36.8 \%$, and $17.1 \%$, respectively ( $p: 0.003$ ). Among proctitis patients, proximal extension was more common in non-smokers (Hazard Ratio: 4.39).

Conclusion: Classification of Crohn's disease patients in BI phenotype should be considered as temporary. Smoking and non-colonic disease are risk factors for behavioural change in BI Crohn's disease patients. Proximal extension is more common in ulcerative colitis patients with proctitis than in those with left-sided colitis. Among proctitis patients, proximal extension is more common in non-smokers. 


\section{Background}

Inflammatory bowel diseases (IBD) are chronic heterogeneous disorders with unpredictable clinical course. Studies on Crohn's disease (CD) behaviour have been hampered by the variability of classifications used and by their unsatisfactory degree of inter-rater agreement [1-4]. The Vienna classification of CD [5] has been proposed in an effort to stratify patients on the basis of widely accepted and reproducible criteria [6]. Although CD location, as defined by the Vienna classification is a relatively stable phenotype, its behaviour varies over time [7]. The majority of patients with B1 phenotype (i.e. non-stricturing non-penetrating disease) will develop over time a stricturing or a penetrating pattern (i.e. B2 and B3 respectively) [7-11]. The environmental and genetic factors affecting disease behaviour evolution are not fully characterized. Ileal location (i.e. L1) $[8,9,11]$, active smoking [8] and number of flares per year [8] were reported to be the major determinants of phenotypic changes. Moreover, some authors suggested that intra-abdominal penetrating disease (IAPD) and perianal penetrating disease (PAPD) represent distinct clinic entities which should be studied independently $[8,11]$.

The extent of colonic involvement in ulcerative colitis (UC) patients is clinically relevant because it has some bearing on the severity of disease and on the needs for medical supervision, drug therapy and surgical excision [12-14]. Although in certain patients with proctitis and left-sided UC, the inflammation spreads proximally, studies on the stability of disease extent over time and risk factors influencing disease extent progression have failed to offer conclusive information [12-21].

We aimed to study the long-term outcome of a homogeneous and well-defined group of Cretan patients with IBD. Particular emphasis was given on the study of rate and risk factors that might influence: change of disease behaviour over time in B1 CD patients; and proximal disease extension in UC patients with proctitis and left-sided colitis at diagnosis;

\section{Methods}

The Gastroenterology Department of the University Hospital of Heraklion has previously conducted prospective and population-based epidemiologic studies of UC and $\mathrm{CD}$ in the prefecture of Heraklion, and participated in the European collaborative study of IBD (EC-IBD) [22-26].

The patient cohort seen at the aforementioned institution has been enriched with cases followed-up at the Gastroenterology Department of Venizelion General Hospital of Heraklion (since its opening at 1996). During the study period these two units were the sole centers providing health care for patients with GI tract problems living in the island of Crete (approximately 600000 people). Clinical details were collected in a special designed form, by patient interview and case note review. Our study protocol was approved by the Ethics Committee of the Medical School of the University of Crete. Written consent was obtained from the patients.

Of the 736 patients listed in the IBD registry (498 with UC and 238 with CD), 372 (256 with UC and 116 with CD) met the following criteria for inclusion in this analysis:

1. A confirmed diagnosis of UC or CD by standard clinical, radiologic, endoscopic and histologic criteria. Patients with an initial diagnosis of UC later changed to $C D$ or vice versa were included in the analysis with the final diagnosis.

2. A satisfactory assessment of the extent of disease at the initial examination in patients with UC and of disease behaviour at diagnosis in patients with $\mathrm{CD}$. Extent, location, and behaviour of UC and CD were evaluated by ileocolonoscopy, upper GI tract endoscopy, enteroclysis, CT scan of abdomen and surgical reports.

3. A follow-up period of at least 60 months. Time of diagnosis was defined as the date of first detection of unequivocal inflammatory abnormalities of the intestine, as assessed from radiologic, endoscopic, or operative observations [9].

The extent of UC was defined as proctitis (rectum involvement), left-sided colitis (involvement up to the splenic flexure) and extensive colitis (involvement proximal to the splenic flexure). Proximal disease extension was defined as the finding at any follow-up colonoscopy of macroscopic inflammation extending beyond $15 \mathrm{~cm}$ from the anus in case of proctitis or beyond the splenic flexure in case of left-sided colitis.

The clinical classification of patients with CD was carried out in strict accordance with the Vienna criteria [5]. In patients with B1 phenotype at diagnosis the first morphologic demonstration of narrowing or penetrating complication was used to mark the occurrence of the complication. Some patients had stricturing disease and then developed a fistula. The sequence was taken into account (i.e. B2 then B3 disease) when the time interval between the two events was greater than one year, otherwise the disease was considered as $\mathrm{B} 3$ [9]. According to previous analyses, patients who were diagnosed with PAPD before CD diagnosis were assumed to have developed their fistula on the day after diagnosis [27]. Only major operations (i.e. bowel resections) were considered as surgical therapy in patients with $\mathrm{CD}$. 
Patients were seen regularly depending on their needs, and had easy access in flare-up episodes. At each visit, symptoms and signs, laboratory and diagnostic examinations, medications and surgery were prospectively registered on a predesigned data sheet. Asymptomatic patients were fully investigated on a yearly basis. Finally, an assessment was made for each year of follow-up, comprising the clinical activity within the year, disease course, intestinal complications, extent of disease, diagnostic procedures, medical treatments, operations, hospitalizations, and outpatient visits.

Chronic continuous course was defined as continuous activity within and during each year of follow-up [28]. Patients were defined as smokers if they consumed at least 7 cigarettes/week and non-smokers if they had never smoked or had stopped smoking before diagnosis [8]. A familial form of the disease was defined as the presence of $\mathrm{UC}$ or $\mathrm{CD}$ in a relative, whatever the familial degree (i.e. parent, child, sibling, grandparent, grandchild, aunt, uncle, and cousin).

\section{Statistical analysis}

Descriptive statistics are expressed as mean and standard deviation or as frequency counts and percentages. Categorical data were analyzed using Pearson's chi-square test. Equalities of means and proportions were tested using Student's $t$ test and analysis of variance with Bonferroni correction for group comparisons. $\mathrm{P}$ values of less than 0.05 were considered statistically significant.
Survival analyses, using the Kaplan-Meier method with log-rank test $[29,30]$, and Cox's proportional hazards model for multivariate analyses [31] were used to study the predefined end-points. Patients with UC were included in these calculations only as long as they had not undergone colectomy. Patients not reaching the end point under consideration were censored at the time of the last clinical follow-up. The multivariate analysis was applied to those of the variables having a $\mathrm{p}=0.2$ in order to identify possible confounding effects [32]. In the multivariate procedure, $\mathrm{p}=0.05$ was considered as the level of significance. Results of analysis are presented as hazard ratios (HR) with $95 \%$ confidence intervals $(95 \% \mathrm{CI})$. The following variables suspected as possible predictors were included in the analysis: age at diagnosis, months from onset to diagnosis, sex, positive family history of IBD, active smoking, disease location in patients with $\mathrm{CD}$, need for immunosuppressive therapy, chronic continuous course, and previous major operation in patients with $\mathrm{CD}$. To examine an age-related effect, patients with $\mathrm{CD}$ were classified as the A1/A2 Vienna classification of under or over 40 years of age. Continuous variables (i.e. age at diagnosis in patients with UC and months from onset to diagnosis in patients with UC and CD) were dichotomized by splitting mean values, which were then compared.

\section{Results}

\section{Crohn's disease patients}

A total of 116 patients with CD were included in the study (Table 1). B1 phenotype accounted for $68.9 \%$ of $\mathrm{CD}$

Table I: Demographic and clinical parameters depending on Crohn's disease behaviour at diagnosis

\begin{tabular}{|c|c|c|c|c|}
\hline \multirow[b]{2}{*}{ Variable } & \multicolumn{4}{|c|}{ Disease behaviour at diagnosis } \\
\hline & $B \mid(\mathbf{N}=\mathbf{8 0})$ & $B 2(\mathbf{N}=\mid 5)$ & B3 $(\mathbf{N}=21)$ & Overall $(\mathbf{N}=|| 6)$ \\
\hline Follow-up (yr) & $10.8 \pm 6.5$ & $9.9 \pm 4$ & $10.4 \pm 6.9$ & $10.5 \pm 6.4$ \\
\hline Males & $46(57.5 \%)$ & $12(80 \%)$ & $12(57.1 \%)$ & $70(60.3 \%)$ \\
\hline Months to diagnosis & $44.6 \pm 42.4$ & $38.8 \pm 45.9$ & $26.2 \pm 36.1$ & $40.6 \pm 42.1$ \\
\hline Al & $60(75 \%)$ & $9(60 \%)$ & $14(66.6 \%)$ & $83(71.5 \%)$ \\
\hline Positive family history & $10(12.5 \%)$ & $2(13.3 \%)$ & $3(14.2 \%)$ & $17(14.6 \%)$ \\
\hline \multicolumn{5}{|l|}{ Location of disease } \\
\hline LI & $12(15 \%)$ & $7(46.6 \%)^{*}$ & $6(28.5 \%)$ & $25(21.5 \%)$ \\
\hline L2 & $25(31.2 \%)$ & $2(13.3 \%)$ & $3(14.2 \%)$ & $30(25.8 \%)$ \\
\hline L3 & $34(42.5 \%)$ & $5(33.3 \%)$ & $12(57.1 \%)$ & $51(43.9 \%)$ \\
\hline L4 & $9(11.2 \%)$ & I (6.6\%) & 0 & $10(8.6 \%)$ \\
\hline Current smoking & $4 \mid(51.2 \%)$ & $6(40 \%)$ & $12(57.1 \%)$ & $59(50.8 \%)$ \\
\hline Continuous course & $17(21.2 \%)$ & $3(20 \%)$ & $3(14.2 \%)$ & $23(19.8 \%)$ \\
\hline Extraintestinal disease $\ddagger$ & $43(53.7 \%)$ & $6(40 \%)$ & $8(38 \%)$ & $57(49.1 \%)$ \\
\hline Immunosuppressives & $38(47.5 \%)$ & $3(20 \%)^{*}$ & $9(42.8 \%)$ & $50(43.1 \%)$ \\
\hline Major operationst & $14(17.5 \%)$ & II $(73.3 \%)^{*}$ & $10(47.6 \%)^{*}$ & $35(30.1 \%)$ \\
\hline At diagnosis & $2(2.5 \%)$ & $9(60 \%)^{*}$ & $7(33.3 \%)^{*}$ & $18(15.5 \%)$ \\
\hline After diagnosis & $12(15 \%)$ & $2(13.3 \%)$ & $3(14.2 \%)$ & $17(14.6 \%)$ \\
\hline
\end{tabular}

Values are given as mean \pm SD or number of patients; Values in parentheses are percentages; $\mathrm{N}$, number; $\mathrm{Al}$, age at diagnosis $\leq 40$ years; $\mathrm{BI}$, nonstricturing non-penetrating disease; B2, stricturing disease; B3, penetrating disease; LI, ileal location; L2, colonic location; L3, ileo-colonic location;

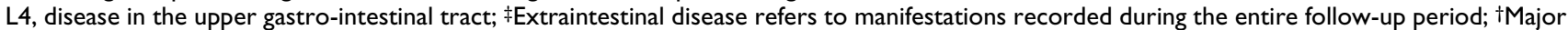
operations refer to bowel resections; $* \mathrm{P}<0.05 \mathrm{vs} \mathrm{BI}$; 
patients at diagnosis (Table 1), for $55.1 \%$ of cases at 5 years after diagnosis (i.e. 64 patients), and for $36.8 \%$ of cases at the end of the study (i.e. 42 patients). Eleven patients with B1 behaviour at diagnosis (13.7\%) developed B2 disease, whereas 27 patients (33.7\%) developed B3 disease. Survival analysis showed that 10 years after diagnosis, the proportion of CD patients still remaining B1 was $38.9 \%$ ( \pm Standard Error (SE): $4.9 \%$ ). The cumulative probability of disease behaviour reclassification in patients with B1 phenotype at diagnosis was $43.6 \%( \pm \mathrm{SE}$ : $6.1 \%$ ) at 10 years after diagnosis (Figure 1).

Factors associated with phenotype change in patients with $\mathrm{B} 1$ disease at diagnosis as identified in univariate analysis are listed in table 2 . Regression model analysis selected active smoking (HR: 3.01; 95\% CI: 1.40-6.45; P: 0.005) and non-L2 disease (HR: 3.01; 95\% CI: 1.16-7.78; P: 0.023 ) as significantly associated with B2 and B3 reclassification in patients with $\mathrm{B} 1$ phenotype at diagnosis. Active smoking (HR: 3.84; 95\% CI: 1.00-14.72; P: 0.049) and L1 disease (HR: 5.76; 95\% CI: 1.65-20.11; P: 0.006) were selected as significantly associated with reclassification from B1 to B2 phenotype, whereas, active smoking (HR: 3.68; 95\% CI: 1.45-9.29; P: 0.006) and non-L2 disease (HR: 3.74; 95\% CI: 1.11-12.56; P: 0.033) were selected as significantly associated with reclassification from B1 to B3 phenotype.

Fifteen patients with initially B1 phenotype (18.7\%) developed IAPD and 12 patients (15\%) PAPD. Regression model analysis selected active smoking (HR: 5.18; 95\%

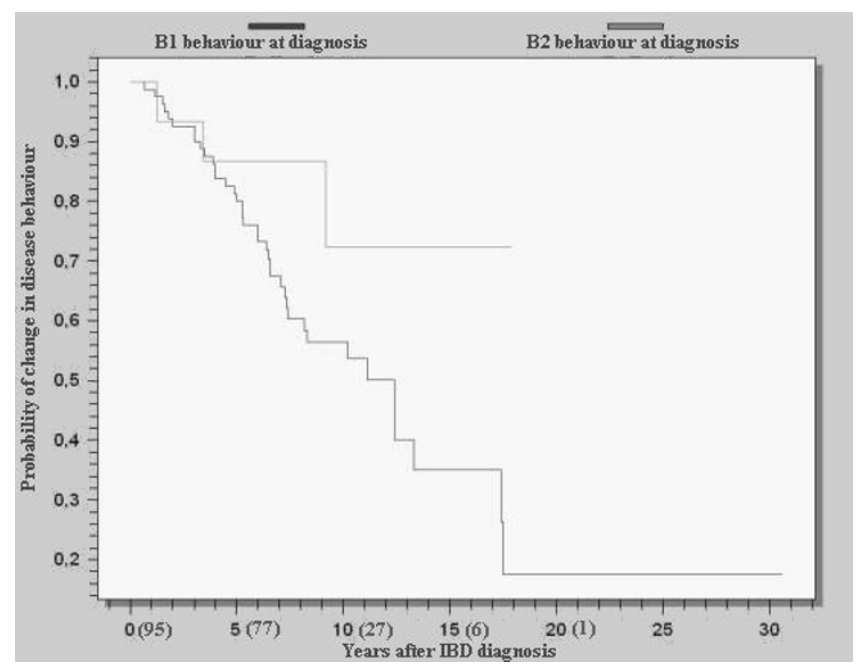

Figure I

Kaplan-Meier estimates of remaining free of change of disease behaviour in patients with BI and B2 phenotypes at diagnosis. The numbers in parentheses (after years from IBD diagnosis) refer to the numbers of patients at risk at the corresponding time points. Log-rank test $p$ value: 0.073 .
CI: 1.12-23.96; P: 0.035), L1 disease (HR: 5.87; 95\% CI: 1.41-24.42; P: 0.015) and chronic continuous course (HR: 4.56; 95\% CI: 1.25-16.61; P: 0.021) as significantly associated with the development of IAPD in patients with initially $\mathrm{B} 1$ phenotype. In univariate analysis the only factor significantly associated with reclassification from B1 to PAPD was active smoking (P: 0.049), which was however rejected from the regression model (HR: 3.21; 95\% CI: 0.96-10.71; P: 0.058) when it was combined with other variables having a p value between $0.51-0.2$.

None of our B1 patients reclassified as B2 became B3, whereas 3 out of 15 patients with B2 phenotype at diagnosis became B3. The cumulative probability of B3 reclassification in patients with B2 phenotype at diagnosis was $27.8 \%$ ( \pm SE: $15.1 \%)$ at 10 years after diagnosis (Figure 1$)$.

At the end of follow-up, 51 patients had B3 phenotype. Overall, B3 phenotype remained unchanged in 23 patients with IAPD and 17 patients with PAPD. However, 5 out of 28 patients (17.8\%) with IAPD developed subsequently PAPD, and 6 out of 23 patients (26\%) with PAPD developed subsequently IAPD. The cumulative probability of appearance of the other penetrating phenotype in an already B3 patient was $22.7 \%( \pm$ SE: $6.7 \%)$ and $32.4 \%( \pm$ SE: $10.8 \%)$ at 5 and 10 years, respectively. The probability of appearance of PAPD in patients with IAPD was not related to age at diagnosis, disease location, or active smoking. Similarly, the probability of appearance of IAPD in patients with PAPD was not related to age at diagnosis or active smoking. Although this was also the case for patients with L1, L2 and L4 disease, L3 patients with PAPD had a greater risk of developing IAPD (P: 0.021).

At 5 years of follow-up, 23 out of 116 CD patients (19.8\%) had experienced a major surgery. The cumulative probability of surgery was $29.7 \%( \pm$ SE: $4.6 \%)$ at 10 years after diagnosis. Patients with L2 disease had a lower risk of surgery than patients with L1 (P: < 0.001), L3 (P: $0.011)$, and L4 disease (P: 0.026). The risk of surgery was also higher in current smokers (P: $<0.001)$. As shown in figure 2, the risk of surgery was significantly higher in patients with current B2 and B3 phenotypes when compared to that of patients with current B1 phenotype, whereas the difference between B2 and B3 curves was insignificant.

Six patients underwent a second operation. The cumulative probability of $2^{\text {nd }}$ intestinal resection was $7.4 \%( \pm \mathrm{SE}$ : $5 \%)$ and $17.2 \%( \pm$ SE: $7.9 \%)$ at 5 and 10 years after $1^{\text {st }}$ intestinal resection, respectively.

\section{Ulcerative colitis patients}

A total of 256 patients with UC were included in the study (Table 3). During follow-up, proximal disease extension 
Table 2: Univariate analysis of risk of change of disease behaviour in patients with B I disease at diagnosis

\begin{tabular}{|c|c|c|c|}
\hline & $\begin{array}{l}\text { Patients without change of disease behaviour } \\
(N=42)\end{array}$ & $\begin{array}{l}\text { Patients with change of disease behaviour } \\
(N=38)\end{array}$ & $\mathbf{P} \S$ \\
\hline Males & $26(61.9 \%)$ & $20(52.6 \%)$ & $0.180 \dagger$ \\
\hline Months to diagnosis & $49.2 \pm 43.5$ & $39.6 \pm 41.2$ & NS \\
\hline Al & $29(69 \%)$ & 31 (8I.5\%) & $0.147 \dagger$ \\
\hline Positive family history & $4(9.5 \%)$ & $6(15.7 \%)$ & NS \\
\hline \multicolumn{4}{|c|}{ Location of disease } \\
\hline $\mathrm{LI}$ & $3(11.9 \%)$ & $9(23.6 \%)$ & 0.005 \\
\hline L2 & $20(47.6 \%)$ & $5(13.1 \%)$ & 0.006 \\
\hline L3 & $15(35.7 \%)$ & $19(50 \%)$ & NS \\
\hline L4 & $4(9.5 \%)$ & $5(13.1 \%)$ & NS \\
\hline Current smoking & $13(30.9 \%)$ & $28(73.6 \%)$ & 0.001 \\
\hline Continuous course & $4(9.5 \%)$ & $13(34.2 \%)$ & 0.016 \\
\hline Immunosuppressives & II (26.1\%) & $9(23.6 \%)^{*}$ & NS \\
\hline Surgery at diagnosis $\ddagger$ & I (2.3\%) & I (2.6\%) & NS \\
\hline
\end{tabular}

Values are given as mean \pm SD or number of patients; Values in parentheses are percentages; N, number; $\mathrm{Al}$, age at diagnosis $\leq 40$ years; LI, ileal location; L2, colonic location; L3, ileo-colonic location; L4, disease of the upper gastro-intestinal tract; *Data collected until change of disease

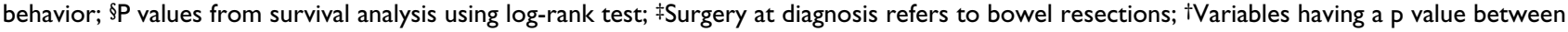
$0.5 \mathrm{I}$ and 0.2 , although insignificant, were included in the regression analysis to avoid confounding effects;

was documented in 25 out of 62 patients (40.3\%) with proctitis and in 26 out of 124 patients (20.9\%) with leftsided colitis. At 5 years of follow-up, proximal extension was documented in 11 out of 62 patients with proctitis $(17.7 \%)$ and in 7 out of 124 patients with left-sided colitis (5.6\%). The cumulative probability of proximal extension in patients with proctitis was $36.8 \%( \pm$ SE: $7.1 \%)$ at 10 years after diagnosis (Figure 3 ). In contrast, the cumulative probability of proximal extension in patients with left-sided colitis was significantly lower, $17.1 \%( \pm$ SE: $3.8 \%$ ) at 10 years after diagnosis (Figure 3 ). None of our proctitis patients eventually underwent colectomy. In contrast, one patient with left-sided colitis at diagnosis and proximal disease extension during follow-up, and two other left-sided colitis patients without further spread of the disease within the observation period were operated on. The 10 year cumulative probability of surgery in our ulcerative colitis patient cohort was $2.9 \%( \pm$ SE: $1.7 \%)$ (years refer to time interval after the initial 5 year period of minimum follow-up from diagnosis), whereas, the cumulative probability of colorectal cancer was $4.5 \%( \pm$ SE: $3.6 \%)$ at 20 years

Factors associated with disease progression in proctitis patients as identified in univariate analysis are listed in table 4. Regression model analysis selected non-smoking as significantly associated with disease progression in patients with proctitis (HR: 4.39; 95\% CI: 1.02-18.79; P: $0.046)$. None of the variables under study was significantly associated with disease progression in patients with left-sided colitis.

\section{Discussion}

Many patients with severe GI problems from other parts of mainland Greece seek medical care in Athens, thus by strict criteria the patients included in series originating from referral Athenian hospitals cannot be considered to be a representative sample for all cases with IBD in Greece [33-37]. It is a well known fact that patients with benign clinical course are under-represented at a tertiary referral center [38]. The advantage of the present study is that, our population is dispersed over a small geographical area and referred to only two Gastroenterology Units which have registered practically all patients with IBD in Crete.

\section{Crohn's disease}

There is only one study analyzing the natural history of CD in Greece [33]. In this series, only crude rates were reported, and emphasis was given on disease location, not behaviour.

Progression over time of CD pathologic changes has been suggested in a previous report by Kelly et al [39]. Other series, using the Vienna $[7,9,11]$ or other classifications $[27,40]$ have also focused on the changing nature of $\mathrm{CD}$ over time. Although our results fit well with those previously reported, they should be interpreted with caution as only 22 patients with $\mathrm{B} 1$ behaviour and 5 patients with $\mathrm{B} 2$ behaviour were available for follow-up at 10 years after diagnosis. Some authors found that patients who are classified as B2 at diagnosis tend to remain B2 over time $[8,41]$. Although these observations are suggestive more of a parallel than of a sequential progression from B1 to 


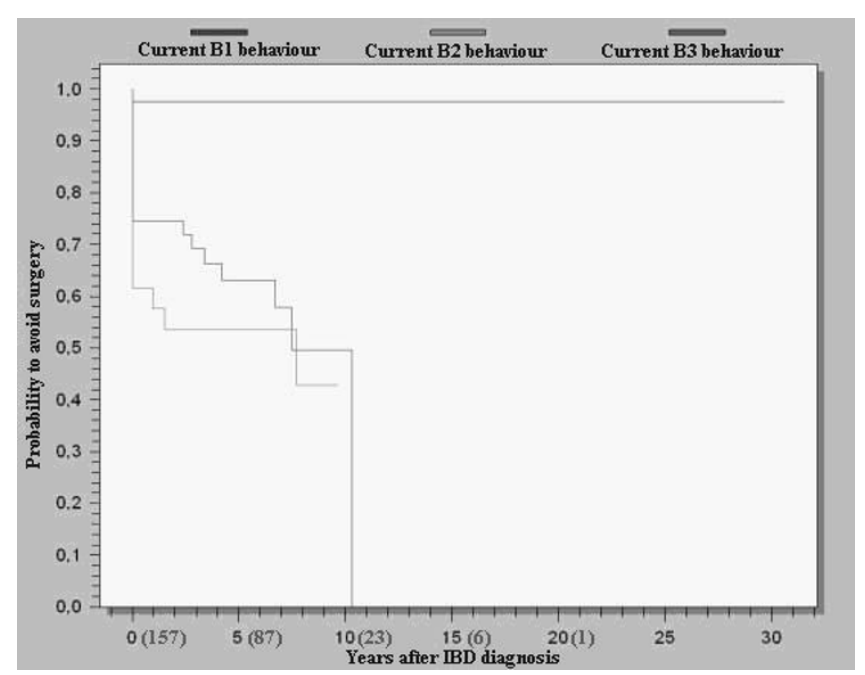

Figure 2

Kaplan-Meier estimates of remaining free of surgery with regard to current disease behaviour. In patients with $\mathrm{BI}$ disease (upper curve), years refer to years after diagnosis in those with stable behaviour, and to years until change of behaviour in those reclassified; In patients with B2 disease (lower curve), years refer to years after diagnosis in cases with stable B2 phenotype, and to years after change of disease behaviour from $\mathrm{BI}$ to $\mathrm{B} 2$ in those reclassified; In patients with B3 disease (middle curve), years refer to years after diagnosis in cases with initial B3 phenotype, and to years after change of disease behaviour form BI or B2 to B3 in those reclassified; The numbers in parentheses (after years from IBD diagnosis) refer to the numbers of patients at risk at the corresponding time points. The corresponding logrank test $P$ values are: $<0.00$ I (BI vs $B 2),<0.00$ I (BI vs B3), 0.359 (B2 vs B3).

either B2 or B3 behaviours, it is quite clear that at least some patients with stricturing behaviour at presentation will finally develop penetrating disease $[8,41,42]$.

An important factor for determining disease behaviour is the location of lesions. In our series, active smoking and L1 or non-L2 disease were associated with change of disease behaviour in patients with B1 phenotype at diagnosis. Location and smoking have also been reported by others as factors associated with complicated CD $[8,9,11,40,43,44]$. Tobacco use has been a risk factor for ileal rather than colonic-only disease [45-47].

The cumulative probability of surgery in our CD patients was lower than that reported in other series [48-51]. Once again, our results should be interpreted with caution as only 43 patients were available for follow-up at 10 years after diagnosis. As expected, the probability of surgery was significantly higher in patients with either B2 or B3 phenotypes (Figure 2). The probability of surgery in B1 patients without change of disease behaviour was mini-

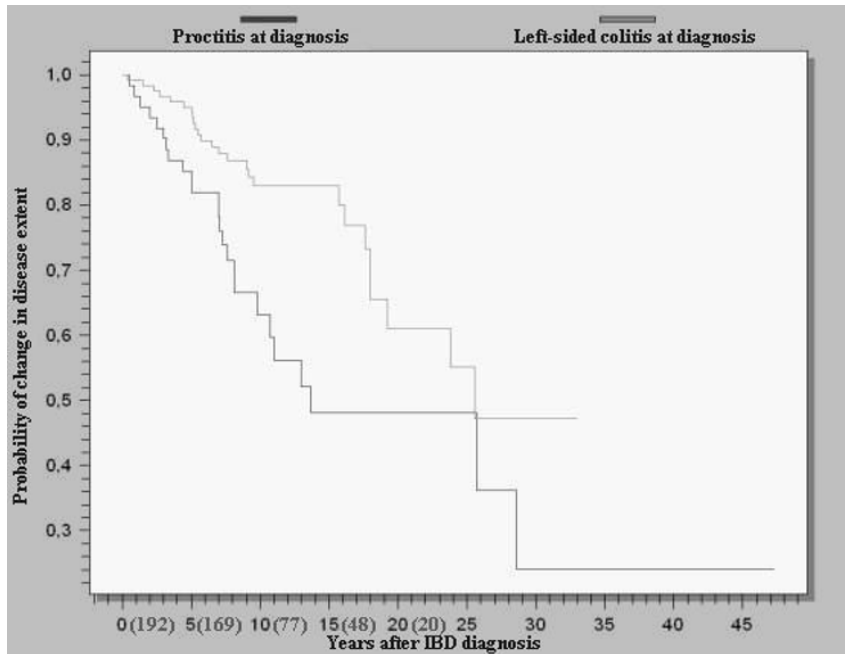

Figure 3

Kaplan-Meier estimates of remaining free of proximal disease extension in patients with proctitis and left-sided colitis at diagnosis. The numbers in parentheses (after years from IBD diagnosis) refer to the numbers of patients at risk at the corresponding time points. Log-rank test $p$ value: 0.003 .

mal, a finding quite similar to that previously reported by others $[11,49]$. Smoking has been previously shown to be associated with increased risk of surgery in CD patients $[40,45,47,52,53]$. The lower probability of surgery in patients with colonic disease has been previously reported by other authors using different classifications $[40,48,50,54,55]$.

The risk for a second resection in our patients previously operated on for CD was lower than that reported in other series $[53,56]$. Previous reports using different classifications identified more frequent reoperation in those with perforating disease $[1,57,58]$, but others have failed to confirm this association $[59,60]$.

Both intra-abdominal and perianal fistulas were classified by the Vienna Working Party Group as penetrating disease [5]. However, some studies suggested that they represent distinct entities $[8,11,61]$. We found that in a significant proportion of B3 patients both penetrating phenotypes appear. Although this was also the case in other reports, in some series no data were clearly reported $[27,62]$, whereas in other series only crude rates were reported $[8,9,11,49,63]$.

\section{Ulcerative colitis}

There are four Athenian studies investigating the clinical course of UC [34-37]. In all these series only crude rates were reported. The age and distribution of macroscopic inflammation at presentation in our patient cohort fits well with that reported in other series $[25,26]$. The rate of 
Table 3: Demographic and clinical parameters depending on ulcerative colitis extent at diagnosis

\begin{tabular}{lllll}
\hline Variable & Proctitis (N = 62) & Left-sided colitis (N = I24) & Extensive colitis (N = 70) & Overall (N = 256) \\
\hline Follow-up (yr) & $11.3 \pm 7.4$ & $12.5 \pm 7.1$ & $12.5 \pm 8.2$ & $12.2 \pm 7.5$ \\
Males & $39(62.9 \%)$ & $73(58.8 \%)$ & $42(60 \%)$ & $154(60.1 \%)$ \\
Months to diagnosis & $24.6 \pm 40$ & $8.9 \pm 13.7 *$ & $7.7 \pm 15.8^{*}$ & $12.4 \pm 24.3$ \\
Age at diagnosis (yr) & $38.3 \pm 14.8$ & $43.3 \pm 15.6$ & $40.3 \pm 16.3$ & $41.3 \pm 15.7$ \\
Positive family history & $8(12.9 \%)$ & $17(13.7 \%)$ & $9(12.8 \%)$ & $34(13.2 \%)$ \\
Current smoking & $16(25.8 \%)$ & $20(16.1 \%)$ & $15(21.4 \%)$ & $51(19.9 \%)$ \\
Continuous course & $4(6.4 \%)$ & $9(7.2 \%)$ & $13(18.5 \%)^{*} \neq$ & $26(10.1 \%)$ \\
Extraintestinal disease $\dagger$ & $11(17.7 \%)$ & $27(21.7 \%)$ & $16(22.8 \%)$ & $54(21 \%)$ \\
Immunosuppressives & $3(4.8 \%)$ & $12(9.6 \%)$ & $16(22.8 \%)^{*} \neq$ & $31(12.1 \%)$ \\
Surgery & 0 & $3(2.4 \%)$ & $3(4.2 \%)$ & $6(2.3 \%)$ \\
\hline
\end{tabular}

Values are given as mean $\pm S D$ or number of patients; Values in parentheses are percentages; $N$, number; tExtraintestinal disease refers to manifestations recorded during the entire follow-up period; * $P<0.05$ vs proctitis; $\ddagger P<0.05$ vs left-sided colitis;

colectomy seems quite low in our patient cohort, especially when compared to other much larger series [12]. However, the rate of colectomy after 5 years is well known to be quite small, about $1 \%$ per year [64,65], and this low rate of colectomy equally applies to patients with initial distal disease and those with initial pancolitis [64]. The cumulative probability of colorectal cancer in our patients falls within the wide confidence intervals calculated by others $[65,66]$.

Conflicting data exist on the rate of proximal disease extension of ulcerative proctitis. [13-16,20,21]. When considering only those two studies in which diagnosis and disease progression were confirmed using endoscopy and survival analysis was carried out, the cumulative rates of proximal extension was reported to range between 30 and $54 \%$ at 10 years, and between $50 \%$ and $84 \%$ at 20 years after diagnosis [20,21]. Our results fit well with those previously reported, however only 19 patients with proctitis at diagnosis were available for follow-up at 10 years after diagnosis. We found that the risk of progression was higher in non-smokers, a finding previously confirmed by some $[18,20]$ but not all authors [13]. There are several possible explanations for these conflicting results.
Some are related to differences in disease extent definition (true proctitis [15,18-21] vs proctosigmoiditis [12-14]) and means of follow-up surveillance (endoscopic [17,1921] vs radiologic [18] vs a combination of sigmodoscopy and barium enema [12-15]). Furthermore, there is poor agreement between extent assessed by histology and endoscopy both at diagnosis and at follow-up $[17,19,25]$.

Fifty eight of our ulcerative colitis patients were available for follow-up at 10 years after diagnosis. Thus, we have found the cumulative probability of proximal extension in these patients to be $17.1 \%$ at 10 years after diagnosis. Others reported cumulative rates ranging between $14 \%$ and $32 \%$ at 10 years after diagnosis $[13,14]$. However, these figures were evaluated using barium enemas and calculated for mixed groups of patients with proctitis and procto-sigmoiditis [13], or with left-sided and extensive colitis at diagnosis [14]. We were unable to find a single demographic or clinical factor associated with change of disease extent from left-sided to extensive colitis.

\section{Conclusion}

Classification of Crohn's disease patients in B1 phenotype should be considered as temporary. Smoking and non-

Table 4: Univariate analysis of overall risk for proximal extension in patients with proctitis at diagnosis

\begin{tabular}{llll}
\hline & Patients with disease progression $(\mathbf{N}=25)$ & Patients without disease progression (N = 37) & P $\S$ \\
\hline Males & $15(60 \%)$ & $24(64.8 \%)$ & $\mathrm{NS}$ \\
Urban residence & $19(76 \%)$ & $21(56.7 \%)$ & $0.200 \dagger$ \\
Months to diagnosis & $21 \pm 50.4$ & $27.1 \pm 31.7$ & $0.125 \dagger^{\dagger}$ \\
Age at diagnosis $(y r)$ & $43.8 \pm 15.4$ & $34.6 \pm 13.4$ & $\mathrm{NS}$ \\
Positive family history & $2(8 \%)$ & $6(16.2 \%)$ & $\mathrm{NS}$ \\
Current smoking & $2(8 \%)$ & $14(37.8 \%)$ & 0.042 \\
Previous appendectomy & $2(8 \%)$ & $2(5.4 \%)$ & $\mathrm{NS}$ \\
Chronic continuous course & $3(12 \%)$ & $1(2.7 \%)$ & $0.189 \dagger$ \\
Immunosuppressive drugs & $0 *$ & $1(2.7 \%)$ & $\mathrm{NS}$ \\
\hline
\end{tabular}

Values are given as mean \pm SD or number of patients; Values in parentheses are percentages; $N$, number; *Data collected until change of disease extent; $\$ \mathrm{P}$ values from survival analysis using log-rank test; $\uparrow$ Variables having a $\mathrm{P}$ value between $0.5 \mathrm{I}$ and 0.2 , although insignificant, were included in the regression analysis to avoid confounding effects; 
colonic disease are risk factors for behavioural change in B1 Crohn's disease patients. At least some patients with stricturing behaviour will finally develop penetrating disease. In a significant proportion of $\mathrm{B} 3$ patients both penetrating phenotypes appear. Proximal extension is more common in ulcerative colitis patients with proctitis than in those with left-sided colitis. Among proctitis patients, proximal extension is more common in non-smokers. Further studies are required to identify factors associated with proximal disease extension in ulcerative colitis patients with left-sided colitis at diagnosis.

\section{Abbreviations}

IBD, inflammatory bowel diseases; $\mathrm{CD}$, Crohn's disease; UC, ulcerative colitis; IAPD, intra-abdominal penetrating disease; PAPD, perianal penetrating disease; HR, hazard ratios

\section{Competing interests}

The author(s) declare that they have no competing interests.

\section{Authors' contributions}

CC: carried out the collection, statistical analysis and interpretation of data and drafting the manuscript

MR: has made substantial contributions to conception and design and revising the manuscript

SP: carried out the collection of data, the endoscopic and clinical diagnosis of the first IBD patients

GP: has been involved in the collection of data from Venizelion Hospital

IM: has been involved in acquisition of data

JR: carried out the majority of surgical procedures in all IBD patients

HM: has been involved in the collection of data from the area of Rethymnon

EK: the supervisor, has given final approval of the version to be published

\section{References}

I. Greenstein AJ, Lackman P, Sachar DB, Springhorn J, Heimann T, Janowitz HD, Aufses $A H$ Jr: Perforating and non-perforating indications for repeated operations in Crohn's disease: evidence for two clinical forms. Gut 1988, 29:588-592.

2. Sachar DB, Andrews HA, Farmer RG, Pallone F, Pena AS, Prantera C: Proposed classification of patient subgroups in Crohn's disease. Gastroenterol Intern 1992, 5:141-154.

3. Greenway SE, Buckmire MA, Marroquin C, Jadon L, Rolandelli RH: Clinical subtypes of Crohn's disease according to surgical outcome. J Gastrointest Surg 1999, 3:|45-|5I.
4. Steinhart AH, Girgrah N, McLeod RS: Reliability of a Crohn's disease clinical classification scheme based on disease behaviour. Inflamm Bowel Dis 1998, 4:228-234.

5. Gasche C, Scholmerich J, Brynskov J, D'Haens G, Hanauer SB, Irvine EJ, Jewell DP, Rachmilewitz D, Sachar DB, Sandborn WJ, Sutherland LR: A simple classification of Crohn's disease: report of the working party of the world congress of gastroenterology, Vienna I 998. Inflamm Bowel Dis 2000, 6:8-I5.

6. Achkar JB, Brzezinski A: Interobserver agreement for disease behaviour phenotype in Crohn's disease. Gastroenterology 2002, I 22(suppl):WI293.

7. Louis E, Collard A, Oger AF, Degroote E, Aboul Nasr El, Yafi FA Belaiche J: Behaviour of Crohn's disease according to the Vienna classification: changing pattern over the course of the disease. Gut 200I, 49:777-782.

8. Louis E, Michel V, Hugot JP, Reenaers C, Fontaine F, Delforge M, EI Yafi F, Colombel JF, Belaiche J: Early development of stricturing or penetrating pattern in Crohn's disease is influenced by disease location, number of flares, and smoking but not by NOD2/CARD I5 genotype. Gut 2003, 52:552-557.

9. Cosnes J, Cattan S, Blain A, Beaugerie L, Carbonnel F, Parc R, Gendre JP: Long-term evolution of disease behaviour of Crohn's disease. Inflamm Bowel Dis 2002, 8:244-250.

10. Freeman HJ: Natural history and clinical behaviour of Crohn's disease extending beyond two decades. I Clin Gastroenterol 2003, 37:216-219.

II. Smith BR, Arnott RID, Drummond HE, Nimmo ER, Satsangi J: Disease localization, Anti-Saccharomyces cerevisiae antibody, and NOD2/CARDI 5 genotype influence the progression of disease behaviour in Crohn's disease. Inflamm Bowel Dis 2004, 10:521-528.

12. Farmer RG, Easley KA, Rankin GB: Clinical patterns, natural history, and progression of ulcerative colitis. A long-term follow-up of I I I 6 patients. Dig Dis Sci 1993, 38: | | 37- | | 46.

13. Ayres RC, Gillen CD, Walmsley RS, Allan RN: Progression of ulcerative proctosigmoiditis: incidence and factors influencing progression. Eur J Gastroenterol Hepatol 1996, 6:555-558.

14. Langholz E, Munkholm P, Davidsen M, Nielsen $\mathrm{OH}$, Binder V: Changes in extent of ulcerative colitis. A study on the course and prognostic factors. Scand J Gastroenterol 1996, 3 I:260-266.

I5. Powell-Tuck J, Ritchie JK, Lennard-Jones JE: The prognosis of idiopathic proctitis. Scand J Gastroenterol 1977, I 2:727-732.

16. Sinclair TS, Brunt PW, Mowatt NAG: Non-specific proctocolitis in northeastern Scotland: a community study. Gastroenterology 1983, 85: I-II.

17. Niv Y, Bat L, Ron E, Theodor E: Change in the extent of colonic involvement in ulcerative colitis: a colonoscopic study. $\mathrm{Am} \mathrm{J}$ Gastroenterol 1987, 82: I046-I05I.

18. Samuelsson SM, Ekbom A, Zack M, Helmick CG, Adami HO: Risk factors for extensive ulcerative colitis and ulcerative proctitis: a population based case-control study. Gut 199I, 32: $1526-1530$.

19. Moum B, Ekbom A, Vatn MH, Elgjo K: Change in the extent of colonoscopic and histological involvement in ulcerative colitis over time. Am J Gastroenterol 1999, 94:1564-I569.

20. Meucci G, Vecchi M, Astegiano M, Beretta L, Cesari P, Dizioli P, Ferraris $L$, Panelli MR, Prada A, Sostegni $R$, de Franchis $R:$ The natural history of ulcerative proctitis: A multicenter, retrospective study. Am J Gastroenterol 2000, 95:469-73.

21. Pica R, Paoluzi OA, lacopini F, Marcheggiano A, Crispino P, Rivera M, Bella A, Consolazio A, Paoluzi P: Oral mesalazine (5-ASA) treatment may protect against proximal extension of mucosal inflammation in ulcerative proctitis. Inflamm Bowel Dis 2004, 10:731-6.

22. Manousos ON, Giannadaki E, Mouzas IA, Tzardi M, Koutroubakis I, Skordilis P, Vassilakis S, Kouroumalis E, Vlachonikolis IG: Ulcerative colitis is as common in Crete as in Northern Europe: a 5-year prospective study. Eur J Gastroenterol Hepatol 1996, 8:893-8.

23. Manousos ON, Koutroubakis I, Potamianos S, Roussomoustakaki M, Gourtsoyiannis N, Vlachonikolis IG: A prospective epidemiologic study of Crohn's disease in Heraklion, Crete. Scand J Gastroenterol 1996, 3 1:599-603.

24. Shivananda S, Lennard-Jones J, Logan R, Fear N, Price A, Carpenter L, van Blakenstein $M$ : Incidence of inflammatory bowel disease across Europe: is there a difference between north and 
south? Results of the European collaborative study on inflammatory bowel disease (EC-IBD). Gut 1996, 39:690-7.

25. Lennard-Jones JE, Shivananda S, the EC-IBD study group: Clinical uniformity of inflammatory bowel disease at presentation and during the first year of disease in the north and south of Europe. Eur J Gastroenterol Hepatol 1997, 9:353-359.

26. Witte J, Shivananda E, Lennard-Jones JE, Beltrami M, Politi P, Bonanomi A, Tsianos EV, Mouzas I, Schultz TB, Monteiro E, Clofent J, Odes S, Limonard CB, Stockbrugger RW, Russel MG: Disease outcome in inflammatory bowel disease: Mortality, morbidity, and therapeutic management of a 796-person inception cohort in the European Collaborative Study on Inflammatory Bowe Disease (EC-IBD). Scand J Gastroenterol 2000, 35: I 272-I 277.

27. Swartz DA, Loftus EV Jr, Tremaine WJ, Panaccione R, Harmsen WS, Zinsmeister AR, Sandborn W]: The natural history of fistulizing Crohn's disease in Olmsted County, Minnesota. Gastroenterology 2002, I 22:875-880.

28. Munkholm P, Langholz E, Davidsen M, Binder V: Disease activity courses in a regional cohort of Crohn's disease patients. Scand I Gastroenterol 1995, 30:699-706.

29. Kaplan EL, Meier P: Non parametric estimation from incomplete observations. J Am Stat Assoc 1958, 53:457-48।.

30. Mantel N: Evaluation of survival data and two new rank order statistics arising in its consideration. Cancer Chemother Rep 1966, 50:163-170.

31. Cox DR: Regression models and life tables. J R Stat Soc 1972 34: $187-220$.

32. Mickey RM, Greenland S: The impact of confounder selection criteria on effect estimation. Am J Epidemiol 1989, I 29: | 25- I37.

33. Triantafillidis JK, Emmanouilidis A, Manousos ON, Nikolakis D, Kogevinas M: Clinical patterns of Crohn's disease in Greece: a follow-up study of I55 cases. Digestion 2000, 6 I: 12 I- 128.

34. Emmanouilidis A, Manousos ON, Papadimitriou C, Triantafillidis JK: Ulcerative colitis in Greece: course and prognostic factors. Digestion 1988, 39:181-6.

35. Manousos ON, Triantafillidis JK, Emmanouilidis A, Papademitriou C: Ulcerative colitis in Greece. Epidemiological and clinica data. Scand J Gastroenterol 1989, I 7 0:25-6.

36. Triantafillidis JK, Emmanouilidis A, Manousos ON, Pomonis E, Tsitsa C, Cheracakis P, Barbatzas C: Ulcerative colitis in Greece: clinicoepidemiological data, course, and prognostic factors in 4I 3 consecutive patients. / Clin Gastroenterol 1998, 27:204-210.

37. Archimandritis AJ, Kourtesas D, Sougioultzis S, Giontzis A, Grigoriadis $P$, Davaris $P$, Tzivras $M$ : Inflammatory bowel disease in Greece - a hospital based clinical study of 172 consecutive patients. Med Sci Monit 2002, 8:CRI58-64.

38. Zankel E, Rogler G, Andus T, Reng CM, Scholmerich J, Timmer A: Crohn's disease patient characteristics in a tertiary referral center: comparison with patients from a population-based cohort. Eur J Gastroenterol Hepatol 2005, 17:395-40I.

39. Kelly JK, Sutherland LR: The chronological sequence in the pathology of Crohn's disease. J Clin Gastroenterol 1988, 10:28-33.

40. Picco MF, Bayless TM: Tobacco consumption and disease duration are associated with fistulizing and stricturing behaviours in the first 8 years of Crohn's disease. Am J Gastroenterol 2003 98:363-368.

41. Sachar DB: Behaviour of Crohn's disease according to the Vienna classification. Gut 2002, 5 I:6/4-6I5

42. Papi C, Festa V, Fagnani C, Stazi A, Antonelli G, Moretti A, Koch M, Capurso L: Evolution of clinical behaviour in Crohn's disease: predictive factors of penetrating complications. Dig Liver Dis 2005, 37:247-253.

43. Cosnes J, Carbonnel F, Beaugerie L, Le Quintrec Y, Gendre JP: Effect of smoking on the long term course of Crohn's disease. Gastroenterology 1996, I 1 0:424-43 |

44. Cottone M, Rosselli M, Orlando A, Oliva L, Puleo A, Cappello M, Traina M, Tonelli F, Pagliaro L: Smoking habits and recurrence in Crohn's disease. Gastroenterology 1994, 106:643-648.

45. Lindberg E, Jarnerot G, Huitfeldt B: Smoking in Crohn's disease: effect on localisation and clinical course. Gut I992, 33:779-782.

46. Russel MG, Volovics A, Schoon EJ, van Wijlick EH, Logan RF, Shivananda S, Stockbrugger RW: Inflammatory bowel disease: is there any relation between smoking status and disease presentation? European Collaborative IBD study Group. Inflamm Bowel Dis 1998, 4:182-6.
47. Brant SR, Picco MF, Achar JP, Bayless TM, Kane SV, Brzezinski A Nouvet FJ, Bonen D, Karban A, Dassopoulos T, Karaliukas R, Beaty $\mathrm{TH}$, Hanauer SB, Duerr RH, Cho JH: Defining complex contributions of NOD2/CARDI 5 gene mutations, age at onset, and tobacco use on Crohn's disease phenotypes. Inflamm Bowel Dis 2003, 9:28I-289.

48. Munkholm P, Langholz E, Davidsen M, Binder V: Intestinal cancer risk and mortality in patients with Crohn's disease. Gastroenterology 1993, 105: 1716-1723.

49. Veloso FT, Ferreira JT, Barros L, Almeida S: Clinical outcome of Crohn's disease: Analysis according to the Vienna classification and clinical activity. Inflamm Bowel Dis 200I, 7:306-3/3.

50. Agrez MV, Valente RM, Pierce W, Melton J 3rd, van Heerden JA, Beart RW Jr: Surgical history of Crohn's disease in a welldefined population. Mayo Clin Proc 1982, 57:742-752.

51. Silverstein MD, Loftus EV, Sandborn WJ, Tremaine WJ, Feagan BG, Nietert PJ, Harmsen WS, Zinsmeister AR: Clinical course and costs of care for Crohn's disease: Markov model analysis of a population-based cohort. Gastroenterology 1999, I I 7:49-57.

52. Cosnes J, Carbonnel F, Carrat F, Beaugerie L, Cattan S, Gendre J: Effects of current and former cigarette smoking on the clinical course of Crohn's disease. Aliment Pharmacol Ther 1999, I3:|403-|4| I.

53. Chardavoyne R, Flint GW, Pollack S, Wise L: Factors affecting recurrence following resection for Crohn's disease. Dis Colon Rectum 1986, 29:495-502.

54. Binder V, Hendriksen C, Kreiner S: Prognosis in Crohn's disease based on results from regional patient group from the county of Copenhagen. Gut 1985, 26:| 46- I50.

55. Sands BE, Arsenault JE, Rosen MJ, Alsahli M, Bailen M, Banks P, Bensen S, Bousvaros A, Cave D, Cooley JS, Cooper HL, Edwards ST, Farrell RJ, Griffin MJ, Hay DW, John A, Lidofsky S, Olans LB, Peppercorn MA, Rothstein RI, Roy MA, Saletta MJ, Shah SA, Warner AS, Wolf] L, Vecchio J. Winter HS, Zawacki JK: Risk of early surgery for Crohn's disease: Implications for early treatment strategies. Am J Gastroenterol 2003, 98:2712-2718.

56. Nordgren SR, Fasth SB, Oresland TO, Hulten LA: Long-term follow up in Crohn's disease. Scand J Gastroenterol 1994, I I:22-28.

57. Aeberhard P, Berchtold W, Riedtmann HJ, Stadelmann G: Surgical recurrence of peforating and nonperforating Crohn's disease-a study of $10 \mathrm{I}$ surgically treated patients. Dis Colon Rectum 1996, 39:80-87.

58. Lautenbach E, Berlin JA, Lichtenstein GR: Risk factors for early postoperative recurrence of Crohn's disease. Gastroenterology 1998, II 5:259-267.

59. Hamon JF, Carbonnel F, Beaugerie L, Sezeur A, Gallot D, Malafosse $M$, Parc R, Gendre JP, Cosnes J: Comparison of long-term course of perforating and non-perforating Crohn's disease. Gastroenterol Clin Biol 1998, 22:60I-606.

60. Yamamoto T, Allan RN, Keighley MR: Perforating ileocecal Crohn's disease does not carry a high risk of recurrence but usually re-presents as perforating disease. Dis Colon Rectum 1999, 42:519-524.

6I. Vasiliauskas EA, Kam LY, Karp LC, Gaiennie J, Yang H, Targan SR: Marker antibody expression stratifies Crohn's disease into immunologically homogenous subgroups with distinct clinical characteristics. Gut 2000, 47:487-496.

62. Bell SJ, Williams AB, Wisel P, Wilkinson K, Cohen RC, Kamm MA: The clinical course of fistulating Crohn's disease. Aliment Pharmacol Ther 2003, I7: | |45-I I5I.

63. Sachar DB, Bodian CA, Goldstein ES, Present DH, Bayless TM, Picco M, van Hogezand RA, Annese V, Schneider J, Korelitz BI, Cosnes J, Task Force on Clinical Phenotyping of the IOIBD: Is perianal Crohn's disease associated with intestinal fistulization? $\mathrm{Am}$ Gastroenterol 2005, 100: I547-1549.

64. Langholz E, Munkholm P, Davidsen M, Binder W: Colorectal cancer risk and mortality in patients with ulcerative colitis. Gastroenterology 1992, 103: 1444-51.

65. Leijonmarck CE, Persson PG, Hellers G: Factors affecting colectomy rate in ulcerative colitis: an epidemiologic study. Gut 1990, 31:329-333.

66. Eaden JA, Abrams KR, Mayberry JF: The risk of colorectal cancer in ulcerative colitis: a meta-analysis. Gut 200I, 48:526-535. 


\section{Pre-publication history}

The pre-publication history for this paper can be accessed here:

http://www.biomedcentral.com/1471-230X/6/21/pre

pub

Publish with Biomed Central and every scientist can read your work free of charge

"BioMed Central will be the most significant development for disseminating the results of biomedical research in our lifetime. " Sir Paul Nurse, Cancer Research UK

Your research papers will be:

- available free of charge to the entire biomedical community

- peer reviewed and published immediately upon acceptance

- cited in PubMed and archived on PubMed Central

- yours - you keep the copyright

Submit your manuscript here:

http://www.biomedcentral.com/info/publishing_adv.asp
BioMedcentral 